\title{
Gene Expression of the Three Members of Hepatocyte Nuclear Factor-3 Is Differentially Regulated by Nutritional and Hormonal Factors
}

\author{
M Imae, Y Inoue, Z Fu, H Kato and T Noguchi \\ Department of Applied Biological Chemistry, Graduate School of Agricultural and Life Sciences, The University of Tokyo, Bunkyo-ku, \\ Tokyo 113-8657 JAPAN \\ (Requests for offprints should be addressed to T Noguchi)
}

\begin{abstract}
Hepatocyte nuclear factor-3 (HNF-3) belongs to a large family of forkhead transcription factors and is made up of three members (HNF-3 $\alpha,-3 \beta$ and $-3 \gamma$ ). It has been shown that HNF-3 regulates a number of metabolically important genes. However, the mechanisms underlying this regulation of HNF-3 activity by hormones and nutrition have not yet been well elucidated. In attempting to explore the regulation of gene expression of HNF-3 members by physiological status, we analyzed the effects of insulin, dexamethasone and protein malnutrition on the hepatic mRNA level of each member. Male Wistar rats were fed on a $12 \%$ casein diet, $12 \%$ gluten diet (deficient in lysine and threonine) or a protein-free diet for 1 week. The protein-free diet and gluten diet caused a 3.7-fold increase in HNF- $3 \gamma$ mRNA in the liver and did not affect the
\end{abstract}

\section{Introduction}

Hepatocyte nuclear factor-3 (HNF-3) belongs to a large family of forkhead transcription factors that are distinguished by the presence of a winged helix motif / forkhead domain (Lai et al. 1993). The HNF-3 proteins were originally observed as factors mediating the liver-specific expression of the transthyretin gene (Costa et al. 1989). They were later shown to be involved in the regulation of numerous liver-specific and other genes, including genes for tyrosine aminotransferase (TAT) and insulin-like growth factor binding protein-1 (IGFBP-1) (Roux et al. 1995, Allander et al. 1997). Many of these genes are regulated by insulin, glucocorticoid, and nutritional status. For instance, expression of the TAT gene is positively regulated by glucocorticoid and negatively regulated by insulin and malnutrition (Ganss et al. 1994). Transcription of the IGFBP-1 gene is strongly repressed by insulin and enhanced by glucocorticoid and by malnutrition (Goswami et al. 1994). We have shown that the IGFBP-1 gene is highly responsive to protein malnutrition (Takenaka et al. 1996).

Three distinct members of HNF-3 (HNF-3 $\alpha,-3 \beta$ and $-3 \gamma$ ) have been identified so far (Kaestner et al. 1994). Numerous reports have shown that each member plays distinct roles in differentiation, inflammation, cell growth and gene regulation
mRNA level of either HNF-3 $\alpha$ or HNF-3 $\beta$. Daily administration of dexamethasone caused the mRNA levels of HNF-3 $\alpha$ and HNF-3 $\beta$ to increase (2.3- and 1.4-fold, respectively), but had no effect on the HNF-3 $\gamma$ mRNA level. In diabetic rats that had been injected with streptozotocin, an elevation of the hepatic mRNA levels of HNF-3 $\beta$ and HNF-3 $\gamma$ was observed (1.6-and 1.9-fold, respectively). Insulin replacement in the diabetic rats decreased both mRNA levels in a dose-dependent manner. HNF- $3 \alpha$ mRNA was not affected by insulin status. These results show that the genes of the three members of the HNF-3 family respond differently to hormonal and nutritional factors suggesting that the activities of HNF-3 members are regulated, at least in part, by the levels of their gene expression.

Journal of Endocrinology (2000) 167, R1-R5

(Lai et al. 1993). It has been shown that the activity of other members of the family of forkhead transcription factors, including FKHR and AFX, are regulated by means of their phosphorylation status. For example, FKHR is phosphorylated at its serine residue following stimulation by insulin (Nakae et al. 1999). However, the mechanism by which HNF-3 is regulated has been less extensively studied.

In the present study, we have analyzed the effect of insulin, dexamethasone and protein malnutrition on the hepatic mRNA levels of HNF-3 $\alpha,-3 \beta$ and $3 \gamma$. We have found that the gene expressions of members of HNF-3 respond differently to these factors.

\section{Methods}

\section{Animals and experimental design}

Male rats of the Wistar strain with a mean body weight of $120 \mathrm{~g}$ were purchased from Charles Liver Japan (Kanagawa, Japan). The rats were kept in a room maintained at $22 \pm 1^{\circ} \mathrm{C}$ with a 12-h light-dark cycle (12h light, $12 \mathrm{~h}$ dark, lights on at 0800). They were given a $12 \%$ casein diet between 1000 and $1800 \mathrm{~h}$ for 3 days before they were given experimental diets (12\% casein diet (12C), $12 \%$ gluten diet or protein-free diet $(\mathrm{PF})$ ). The experimental diets were given for 7 days on the same schedule, and water was available ad libitum. The 
composition of the experimental diets has been described previously (Takahashi et al. 1990).

At 1130 on day 8, the rats were anesthetized with pentobarbital, and blood was taken from them at the carotid artery. The liver was excised, snap-frozen in liquid nitrogen, and stored at $-80^{\circ} \mathrm{C}$ until the RNA was prepared.

For the analysis of the effect of dexamethasone treatment, rats were injected with $1 \mathrm{mg} / \mathrm{kgBW}$ of dexamethasone (Dex; Sigma) dissolved in $40 \%$ ethanol/60\% phosphate-buffered saline at 1800 daily for 7 days. Rats of the control group were injected with vehicle. They were given $12 \%$ casein or the protein-free diet. Liver sampling on the 8th day was done as described above. Mean body weights on the 8th day were $239 \pm 5 \mathrm{~g}(12 \mathrm{C}), 160 \pm 2 \mathrm{~g}(12 \mathrm{C}+\mathrm{Dex}), 171 \pm 2 \mathrm{~g}(\mathrm{PF})$ and $146 \pm 1 \mathrm{~g}$ $(\mathrm{PF}+$ Dex $)($ mean+S.E.M.). For an insulin-deficiency study, rats were injected with $75 \mathrm{mg} / \mathrm{kgBW}$ of streptozotocin (Sigma) dissolved in $50 \mathrm{mM}$ citrate buffer $(\mathrm{pH} 4.5)$ or vehicle only. After two days, plasma glucose levels were measured by glucose oxidase method (Glucose B-test Wako, Wako Pure Chemical, Japan) to verify diabetic symptoms. During the ensuing seven days, ten rats were given $0.8 \mathrm{U} /$ day human insulin (Sigma) and another ten were given $6.4 \mathrm{U} /$ day insulin intravenously at 1000 . All rats in the groups described here and in the vehicle-treated groups were fed on either the control diet or the protein-free diet. On day 8 , rats were given respective diets for $1.5 \mathrm{~h}$ after insulin treatment and then sacrificed.

All experiments were performed under the guidelines of the Animal Usage Committee of the Faculty of Agriculture, The University of Tokyo.

\section{Solution hybridization/RNase Protection Assay}

Total RNA was prepared from the liver by the acid-guanidiumphenol-chloroform method (Chomczynski et al. 1987) using the TRIzol ${ }^{\mathrm{TM}}$ reagent (GibcoBRL). The concentration of RNA was determined by the absorbance at $260 \mathrm{~nm}$. The integrity and amount of RNA were confirmed by visualization of ribosomal RNAs after electrophoresis on denaturing agarose gels.

Template DNAs for the synthesis of antisense RNA probes were obtained by a reverse transcription-polymerase chain reaction. The position of the amplified cDNA (nucleotide number) and the length of protected bands in the RNase protection assays were as follows: HNF- $3 \alpha$; 711-1104 (Lai et al. 1990), 394 bases, HNF-3ß; 973-1280 (Lai et al. 1991),

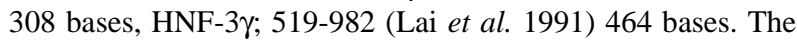
amplified cDNAs were subcloned into a pCRII $^{\mathrm{TM}}$ vector (Invitrogen) and the sequences were confirmed using an automated DNA sequencer (Prism 310, ABI).

A solution hybridization/RNase protection assay was performed as described previously (Kato et al. 1994). Forty (HNF-3s) or ten ( $\beta$-actin) micrograms of the total RNA from the liver of each rat were used in the assays. The bands were visualized and quantified using a Fujix Bas 2000 system (Fuji Film Co. Kanagawa, Japan). Background value of each lane was subtracted independently. All of the data were corrected for the intensities of the bands obtained using a rat $\beta$-actin probe. Lysate RNase protection assays were also performed using the same liver samples to obtain relative mRNA levels per wet tissue weight (Kato et al. 1999).

\section{Statistics}

The results were analyzed statistically using Duncan's multiple range test (Duncan 1955).

\section{Results}

Figure 1 shows the effects of a protein-free (PF) diet and a $12 \%$ gluten $(12 \mathrm{G})$ diet on the hepatic mRNA levels of HNF-3 $\alpha,-3 \beta$ and $-3 \gamma$. Receiving the PF diet or $12 \mathrm{G}$ diet for 1 week did not affect the mRNA levels of HNF-3 $\alpha$ and -3 $\beta$. There was a 3.7fold increase in HNF- $3 \gamma$ mRNA in the PF diet-fed group as compared with the control (12\% casein) diet-fed group. In addition, feeding the $12 \mathrm{G}$ diet, which is deficient in lysine and

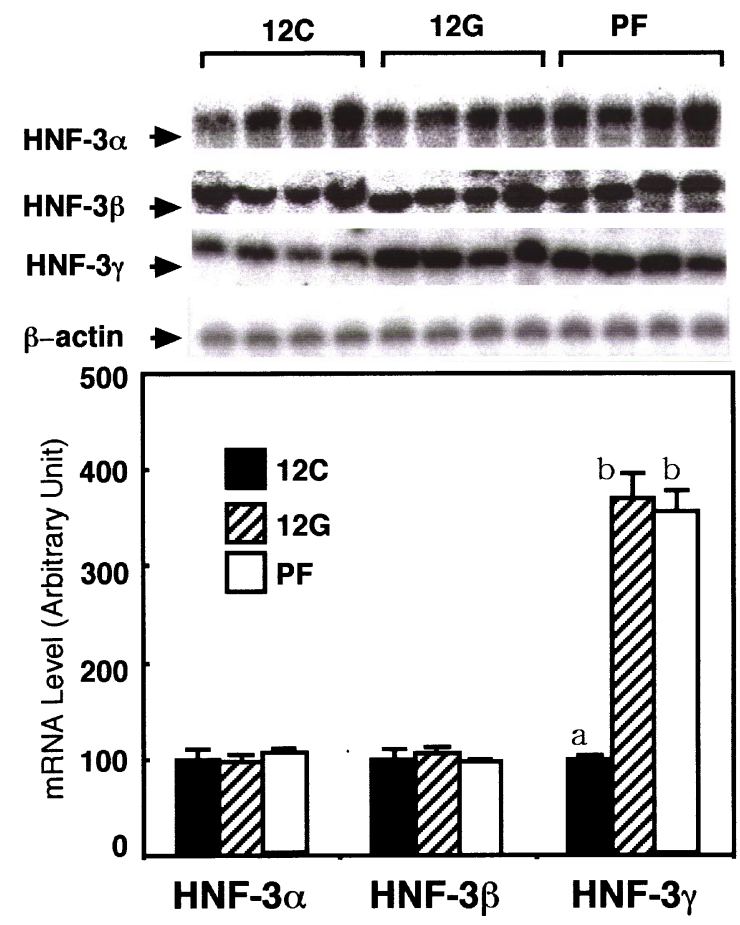

Figure 1 The Effect of a Protein-free Diet on the Hepatic mRNA Levels of the Three Members of HNF-3.

Rats were given a $12 \%$ casein (12C) diet, $12 \%$ gluten diet (12G) or a protein-free (PF) diet between the hours of 1000 to 1800 for 7 days. On the 8th day, the rats were fed their respective diets for $1.5 \mathrm{~h}$, then sacrificed, and their livers were excised for the preparation of total RNA. The levels of mRNA of HNF-3 $\alpha,-3 \beta$, $3 \gamma$ and $\beta$-actin were determined by RNase protection assay. Typical results are shown on the upper panel in which each lane represents a result from an individual rat. The quantitative representations normalized by $\beta$-actin mRNA levels are shown on the lower panel (means and S.E.M.). Means not sharing the same letter are significantly different $(\mathrm{P}<0.05)$. 


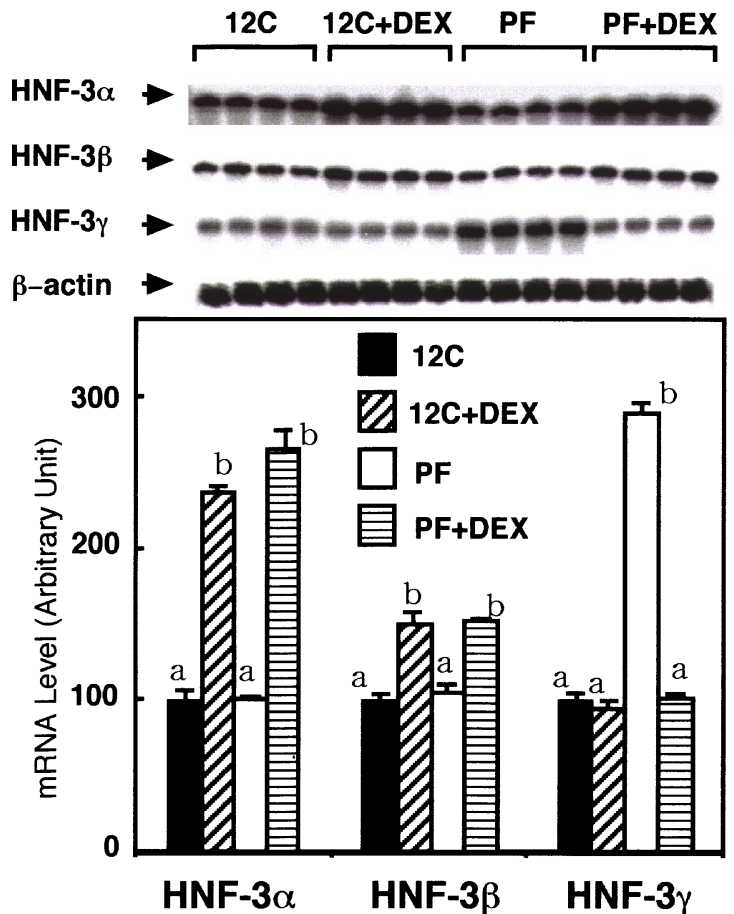

Figure 2 The Effect of Dexamethasone Treatment on Hepatic mRNA Levels of the Three Members of HNF-3.

Rats were given a $12 \mathrm{C}$ or PF diet for 7 days as described in the legend of Figure 1. During this 7-day period, $1 \mathrm{mg} / \mathrm{kgBW}$ of dexamethasone was injected daily. The hepatic levels of mRNA of HNF- $3 \alpha,-3 \beta,-3 \gamma$ and $\beta$-actin were determined by RNase protection assay. Data normalized by $\beta$-actin mRNA levels (means and S.E.M.) are shown. Means not sharing the same letter are significantly different $(P<0.05)$.

threonine, caused a similar magnitude of increase in HNF-3 $\gamma$ mRNA.

We next examined the effect of glucocorticoid and insulin on the hepatic mRNA levels of the three subtypes of HNF-3. Dexamethasone $(1 \mathrm{mg} / \mathrm{kgBW})$ was injected subcutaneously daily for 1 week while the control or PF diet was fed. Dexamethasone caused a 2.3-fold increase in hepatic HNF-3 $\alpha$ mRNA levels and a 1.4-fold increase in HNF- $3 \beta$ mRNA levels (Figure 2). An increase in the mRNA of HNF-3 $\gamma$ was again observed in PF diet-fed rats. Dexamethasone alone had no effect on HNF-3 $\gamma$ mRNA. However, when dexamethasone was administered in PF diet-fed rats, it canceled the effect of PF diet in that the mRNA level did not differ from that of the control group.

Diabetes was induced by intraperitoneal injection of streptozotocin, and the symptoms were verified by measuring the fasting blood glucose. Two days after the injection of STZ, insulin replacement was started by daily intravenous injection ( 0.8 or $6.4 \mathrm{U} /$ day, just before the starting of feeding). Blood glucose levels at the sacrifice $(1.5 \mathrm{~h}$ after injection) were as following; $191 \pm 14$ (normal rats), 1188 \pm 97 (STZ-treated), $518 \pm 108$ (STZ+0.8U insulin), $273 \pm 74$ (STZ+6.4U insulin) (mg/100ml, mean \pm S.E.M.). The blood glucose levels were not significantly different between $12 \mathrm{C}$ - and PF-fed groups (data not shown). Insulin deficiency did not affect HNF-3 $\alpha$ mRNA levels, but caused drastic increases in HNF-3 $\beta$ mRNA in both the control and PF-fed groups (Figure 3). The increase in HNF-3 $\beta$ mRNA was reversed by the replacement of insulin. A similar increase in HNF- $3 \gamma$ mRNA was observed in diabetic rats.

The results above were confirmed by a lysate RNase protection assay where RNA probes were directly added to the lysates of liver samples. (data not shown, ).

\section{Discussion}

The importance of HNF-3 in the regulation of gene expression has manifested itself in many instances. For example, targeted disruption of the HNF- $3 \gamma$ gene results in a decreased expression of several liver-specific genes (Kaestner et al. 1998). HNF-3 $\alpha$ null mice develop a phenotype of impaired glucose homeostasis and neonatal mortality (Kaestner et al.

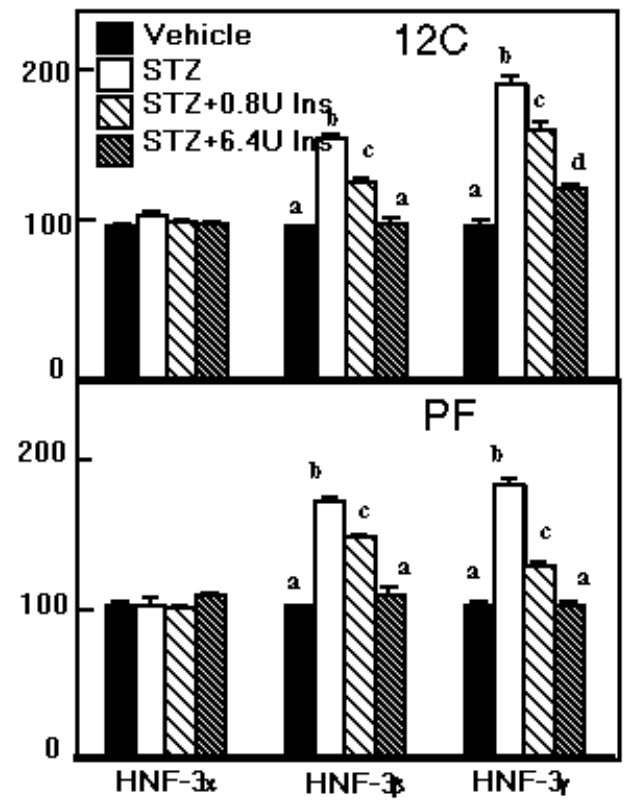

Figure 3 The Effect of Diabetes and Insulin Treatment on the Hepatic mRNA Levels of the Three Members of HNF-3.

Rats were injected with $75 \mathrm{mg} / \mathrm{kgBW}$ of streptozotocin (STZ), kept on $12 \mathrm{C}$ diet for two days, then given a $12 \mathrm{C}$ (upper panel) or PF (lower panel) diet for 7 days as described in the legend of Figure 1. During this 7-day period, STZ-rats were given $0,0.8$ or $6.4 \mathrm{U}$ of insulin at the beginning of feeding. Hepatic levels of the mRNA of HNF- $3 \alpha,-3 \beta,-3 \gamma$ and $\beta$-actin were determined by RNase protection assay. Data normalized by $\beta$-actin mRNA levels (means and S.E.M.) are shown. Means not sharing the same letter are significantly different $(P<0.05)$. 
1999, Shih et al. 1999). HNF-3 has been shown to bind to and regulate the promoters of many genes, including transthyretin, fructose 2,6-bisphosphatase, hexokinase I, tyrosine aminotransferase and IGFBP-1 (Roux et al. 1995, Allander et al. 1997, Wang et al. 1999, Lin et al. 1997).

HNF-3 belongs to a large family of forkhead transcription factors. The mechanisms underlying the activation and inactivation of some of the forkhead transcription factors have been studied mainly with respect to the action of insulin. It has been shown that one of the other forkhead transcription factors, FKHR, is regulated by phosphorylation by Akt/protein kinase B after insulin stimulation (Nakae et al. 1999, Guo et al. 1999). In the case of AFX, another member of the family of forkhead transcription factors, nuclear translocation is also under the control of phosphorylation by protein kinase B (Takaishi et al. 1999). The regulation of the HNF-3 family has not been well investigated. Here we present data suggesting that the activities of HNF-3 members are regulated by alterations in the expression of their respective genes. Gene expression of HNF-3 $\alpha$ was elevated by dexamethasone. The expression of HNF-3 $\beta$ gene was increased by dexamethasone and by diabetes, and that of HNF- $3 \gamma$ was increased by protein malnutrition and diabetes. The regulation of the gene expression of HNF-3 family has not been studied extensively. A change in HNF-3 $\alpha$ gene expression that functioned to regulate transthyretin gene transcription has been reported in the case of an acute-phase response (Qian et al. 1995). The change in the mRNA levels of HNF-3 $\gamma$ in response to alterations in protein nutrition shown here is reminiscent of the way that HNF-1, another liver-specific transcription factor, is regulated by amino acid limitation (Marten et al. 1996).

The possibility that the effect of protein malnutrition on HNF-3 gene expression is manifested by impaired insulin secretion might be excluded because the effect of STZ and protein malnutrition was no parallel. Namely, the observations that protein malnutrition caused an increase in HNF- $3 \gamma$ mRNA but not HNF-3 $\beta$ mRNA and that diabetes increased both mRNAs suggest that signaling mediating protein malnutrition involves a pathway that is independent of insulin signaling. Furthermore, our unpublished observation that the plasma immunoreactive insulin concentration of the rats fed the protein-free diet is not significantly different from that of those fed the casein diet favors this assumption.

The precise role of each member of HNF-3 is far from being clearly determined. A possible explanation for the presence of the three members may be the regulatory role of different genes by an individual member of HNF-3. In some instances, each member of HNF-3 affects the gene expression of a particular gene in opposite ways (Sawaya et al. 1994). The results of the present study suggest that these three members have different roles to play in the adaptation and/or response of animals to various physiological alterations. The distinct and overlapping patterns of activation of each HNF-3 member suggest that members of HNF-3 may integrate and tune the incoming information that indicates the nutritional and hormonal status. Analyses of the concentrations of HNF-3 members using antibodies highly specific to the respective members will promote further understanding of their roles. In addition, a search for other mechanisms by which HNF-3 activity is regulated, including changes of phosphorylation, localization and DNA binding activity, will surely be necessary, although such mechanisms have not up to now been identified in the case of this transcription factor.

The results of the present study suggest that the effects of insulin, glucocorticoid and nutritional alteration on the gene expression of a number of genes are at least in part mediated by changes in the gene expression of distinct members of HNF-3. Further studies that elucidate the mechanisms by which these factors regulate HNF-3 gene expression are necessary in order to identify the 'master gene(s)' of the gene regulation cascade that is triggered by these hormones and nutritional changes.

\section{References}

Allander SV, Durham SK, Scheimann AO, Wasserman RM, Suwanichkul A \& Powell DR 1997 Hepatic nuclear factor 3 and high mobility group I/Y proteins bind the insulin response element of the insulin-like growth factor-binding protein-1 promoter. Endocrinology 138 4291-4300.

Chomczynski P \& Sacchi N 1987 Single-step method of RNA isolation by acid guanidiniumthiocyanate-phenol-chloroform extraction. Analytical Biochemistry 162 156-169.

Costa RH, Grayson DR \& Darnell JE Jr 1989 Multiple hepatocyteenriched nuclear factors function in the regulation of transthyretin and alpha 1-antitrypsin genes. Molecular and Cellular Biology 9 1415-1425.

Duncan DB 1955 Multiple range and multiple F tests. Biometrics 11 42.

Ganss R, Weih F \& Schutz G 1994 The cyclic adenosine 3',5' monophosphate- and the glucocorticoid- dependent enhancers are targets for insulin repression of tyrosine aminotransferase gene transcription. Molecular Endocrinology 8 895-903.

Goswami R, Lacson R, Yang E, Sam R \& Unterman T 1994 Functional analysis of glucocorticoid and insulin response sequences in the rat insulin-like growth factor-binding protein-1 promoter. Endocrinology 134 736-743.

Guo S, Rena G, Cichy S, He X, Cohen P \& Unterman T 1999 Phosphorylation of serine 256 by protein kinase B disrupts transactivation by FKHR and mediates effects of insulin on insulin-like growth factor-binding protein-1 promoter activity through a conserved insulin response sequence. Journal of Biological Chemistry 274 17184-17192.

Kaestner KH, Hiemisch H, Luckow B\& Schutz G 1994 The HNF-3 gene family of transcription factors in mice: gene structure, cDNA sequence, and mRNA distribution. Genomics 20 377-385.

Kaestner KH, Hiemisch H \& Schutz G 1998 Targeted disruption of the gene encoding hepatocyte nuclear factor $3 \gamma$ results in reduced transcription of hepatocyte-specific genes. Molecular and Cellular Biology 18 4245-4251.

Kaestner KH, Katz J, Liu Y, Drucker DJ \& Schutz G 1999 Inactivation of the winged helix transcription factor $\mathrm{HNF} 3 \alpha$ affects glucose homeostasis and islet glucagon gene expression in vivo. Genes and Development 13 495-504. 
Kato H, Faria TN, Stannard B, Roberts CT Jr \& LeRoith D 1994 Essential role of tyrosine residues 1131, 1135, and 1136 of the insulin- like growth factor-I (IGF-I) receptor in IGF-I action. Molecular Endocrinology 8 40-50.

Kato H, Fu Z, Kotera N, Sugahara K \& Kubo T 1999 Regulation of the expression of serotonin $\mathrm{N}$-acetyltransferase gene in Japanese quail (Coturnix japonica): I. Rhythmic pattern and effect of light. Journal of Pineal Research 27 24-33.

Lai E, Prezioso VR, Smith E Litvin O, Costa RH \& Darnell JE Jr 1990 HNF-3A, a hepatocyte-enriched transcription factor of novel structure is regulated transcriptionally. Genes and Development 4 1427-1436.

Lai E, Prezioso VR, Tao W, Chen WS \& Darnell JE Jr 1991 Hepatocyte nuclear factor $3 \alpha$ belong to a gene family in mammals that is homologous to Drosophila homeotic gene fork head. Genes and Development 5 416-427.

Lai E, Clark KL, Burley SK \& Darnell JE Jr 1993 Hepatocyte nuclear factor 3/fork head or 'winged helix' proteins: A family of transcription factors of diverse biologic function. PNAS 9010421 10423.

Lin B, Morris DW \& Chou JY 1997 The role of HNF1alpha, HNF3gamma, and cyclic AMP in glucose-6-phosphatase gene activation. Biochemistry 36 14096-14106.

Marten NW, Sladek FM \& Straus DS 1996 Effect of dietary protein restriction on liver transcription factors. Biochemical Journal $\mathbf{3 1 7}$ (Pt 2) 361-370.

Nakae J, Park BC \& Accili D 1999 Insulin stimulates phosphorylation of the forkhead transcription factor FKHR on serine 253 through a wortmannin-sensitive pathway. Journal of Biological Chemistry 274 15982-15985.

Qian X, Samadani U, Porcella A \& Costa RH 1995 Decreased expression of hepatocyte nuclear factor $3 \alpha$ during the acute-phase response influences transthyretin gene transcription. Molecular and Cellular Biology 15 1364-1376.
Roux J, Pictet R \& Grange T 1995 Hepatocyte nuclear factor 3 determines the amplitude of the glucocorticoid response of the rat tyrosine aminotransferase gene. DNA and Cell Biology $14385-$ 396.

Sawaya PL \& Luse DS 1994 Two members of the HNF-3 family have opposite effects on a lung transcriptional element, HNF-3 alpha stimulates and HNF-3 $\beta$ inhibits activity of region I from the Clara cell secretory protein (CCSP) promoter. Journal of Biological Chemistry 269 22211-22216.

Shih DQ, Navas MA, Kuwajima S, Duncan SA \& Stoffel M 1999 Impaired glucose homeostasis and neonatal mortality in hepatocyte nuclear factor 3alpha-deficient mice. PNAS $9610152-$ 10157.

Takaishi H, Konishi H, Matsuzaki H, Ono Y, Shirai Y, Saito N, Kitamura T, Ogawa W, Kasuga M, Kikkawa U \& Nishizuka Y 1999 Regulation of nuclear translocation of forkhead transcription factor AFX by protein kinase B. PNAS 96 11836-11841.

Takahashi S, Kajikawa M, Umezawa, T, Takahashi S, Kato H, Miura Y, Nam TJ, Noguchi T \& Naito H 1990 Effect of dietary proteins on the plasma immunoreactive insulin-like growth factor1/somatomedin C concentration in the rat. British Journal of Nutrition 63 521-534.

Takenaka A, Mori M, Yamada S, Ohgane J, Takahashi SI and Noguchi T 1996 Nutritional regulation of gene expression of insulin-like growth factor-binding proteins and the acid-labile subunit in various tissues of rats. Journal of Endocrinology 150 33-41.

Wang JC, Stromstedt PE, Sugiyama T \& Granner DK 1999 The phosphoenolpyruvate carboxykinase gene glucocorticoid response unit: identification of the functional domains of accessory factors HNF3 beta (hepatic nuclear factor-3 beta) and HNF4 and the necessity of proper alignment of their cognate binding sites. Molecular Endocrinology 13 604-618. 